
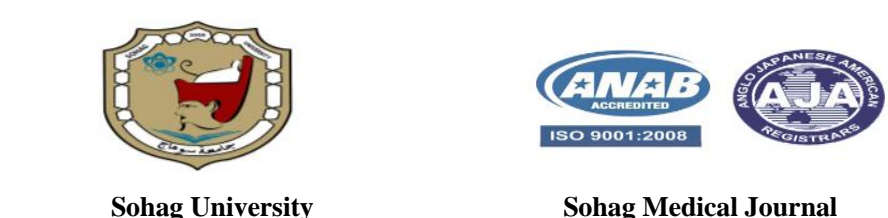

Sohag Medical Journal

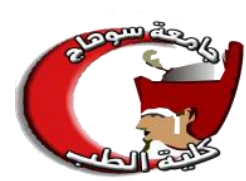

Faculty of Medicine

\title{
Correlation between the activity of lupus nephritis and different ANA antibodies
}

\author{
Alaa Mohamed Hemdan and Sahar Abd Elrahman Alsayed
}

Department of Rheumatology and Rehabilitation, Sohag University

\begin{abstract}
Background: To detect the correlation between the activity of systemic lupus erythematosus especially lupus nephritis with ANA profile (anti-histone, anti-dsDNA, andnucleosome antibodies).

Methods: Clinical and demographic data were analyzed statistically in 70 lupus nephritis patients from October 2018 to July 2019. We used serum test Euroline ANA profile (IgG)to detected the reactivity to a group of 19 autoantibodies. The correlation of the 3 autoantibodies (anti-dsDNA, anti-histone, and anti-nucleosome antibodies)with nephritis was analyzed. Renal biopsies were studied by pathologists. The Immune complex deposition was recognized by immunohistochemistry stain.

Results: Our study detected the correlation of anti-nucleosome,-histone, and - dsDNA antibodies in lupus nephritis diagnosis. Furthermore, our study suggests that we can predict the kidney affection and activity of lupus nephritis by the positive correlation between antinucleosome, -dsDNA, and -histone antibodies, which may make a major addition in the follow-up and treatment of lupus patients. Close reactivity with anti -nucleosome,-dsDNA, and -histone antibodies (3-positive antibodies) in SLE patients was highly related to the pathology of lupus nephritis. Three-pos patients of LN showed highly significant levels of these 3 antibodies manifested by more severe nephropathy and in needing more treatments than non three pos patients of lupus nephritis, which indicating three positive antibodies as a biomarker for lupus nephritis severity.

Conclusions: ANA profile (IgG) especially the 3 autoantibodies (Anti-nucleosome histone and -dsDNA antibodies ) may be used as indicators for severe kidney affection and activity in patients of SLE.

Keywords: Lupus Nephritis, Anti-nucleosome, histone, dsDNA
\end{abstract}

\section{Introduction:}

Systemic lupus erythematosus (SLE) is defined as an autoimmune disease that affects multiples organs, including the heart, joints, liver, lungs, brain, and kidneys. There are some theories about the etiology of SLE one of them: the excessive production of antibodies against nucleic of cell antigens which leads to immune complex deposition in different organs (1, 2).
Lupus nephritis (LN) is the most dangerous and common SLE manifestation, which occurs in about $50-80 \%$ of lupus patients. A major number of lupus patients are resistant to classical treatments, aside from, kidney relapse is the main hazard of poor kidney function $(\mathbf{3}, \mathbf{4})$.

Subsequently, early detection of renal affection of SLE patients and additional treatments are recommended. Specific auto- 
SOHAG MEDICAL JOURNAL

Vol. 25 No. 1 Jan 2021 antibodies have a signal role in the occurrence of SLE. Serum ANA Profile test $(\mathrm{IgG})$ now is used usually to determine a group of autoantibodies against cell nuclei in the blood of patients with autoimmune disorders like SLE. While a sure diagnosis of specific autoimmune disorders still depends on clinical and laboratory findings, for a confirmed diagnosis, renal biopsies are also needful (5). Anti-extractable nuclear antigen and antinuclear antibody testing form the base of a serologic test of SLE. However, the ANA test gives positive titer in autoimmune disorders and other diseases, which sometimes appear positive in normal persons (5). Some types of ANA like antiRNP, anti-Smith, anti-Histon, and antidsDNA antibodies, etc. were determined as highly particular for lupus and their serum levels attended to detect the activity of SLE $(6,7)$.

It is previously documented that, in patients of SLE, co- positivity of anti-nucleosome, anti-dsDNA and anti-histone antibodies is significantly high in LN begining and efficiency, which revealing as a useful index for kidney affection (8).

\section{Aims of the Study:}

To detect the correlation between the activeity of systemic lupus erythematosus especially lupus nephritis with ANA profile (anti-histone,-dsDNA, and- nucleosome antibodies).

\section{Patients and methods:}

\section{Study design:}

This study was a cross-sectional study

\section{Setting:}

This study was conducted from October 2018 to July 2019 in Rheumatology Department, Sohag University Hospital.

\section{Inclusion criteria:}

1. Patients diagnosed as SLE according to SLICC 2012 or ACE/EULAR 2019 classification criteria.
2. Age (17-40) years

3. Patients with disease duration more than 6 months

\section{Exclusion criteria:}

1. Patients with concomitant systemic diseases such as chronic obstructive lung disease, coronary artery disease, cancer, thyroid function disorder, hematological disorders, acute or chronic liver, and renal diseases

2. Other autoimmune diseases including rheumatoid arthritis, systemic lupus erythematosus, scleroderma, mixed conective tissue disease, and polymyositis

3. Patients using contraceptive pills

4. Systemic hypertension

5. Hyperlipidemia

6. Obesity

7. history of smoking

8. Diabetes mellitus

\section{Methods:}

All patients and control cases were subjected to the following:

1. Thorough medical history from the patients

2. Full clinical examination including:

1. General examination and vital signs.

2. Complete rheumatological examination.

3. Ophthalmological examination

4. Dermatological examination

5. Neurological examination.

3. Routine investigations (complete blood picture, erythrocyte sedimentation rate, liver functions, and kidney investigation including urine analysis, a 24-hour collection of protein in the urine, serum creatinine).

4. Renal biopsy.

5. ANA by IF.

6. ANA profile for the most common 19 autoantibodies especially three autoantibodies (anti-nucleosome, antihistone, and anti-dsDNA) which are 
SOHAG MEDICAL JOURNAL

Vol. 25 No. 1 Jan 2021 divided into three pos and non-pos SLE patients especially LN, we considered the non-3pos patient whose serum level of three antibodies (negative or single, double association with them).

\section{Ethical considerations:}

- our study was confirmed by the Scientific Ethical Committee of the Faculty of Medicine, Sohag University.

- all patients in the study wrote informed consent after explaining the aim of the study.

\section{Assays of anti-nuclear antibodies pr- ofile:}

ANA profile kit used to detect (histone, nucleosome, dsDNA, PCNA, mitochondrial-2, ribosomal-p, DFS-70, Sm, RNP, Sm/ RNP, Jo-1, Scl-70, Ro-52, Ro60KD, La, Ku, PM-scl100, CENP-A/B) according to EUROLINE instruction and read by EUROBlotMaster (Lübeck, Germany).

\section{Evaluation of kidney pathology:}

The specimens were taken from the kidney were examined by direct immunehistochemistry stain under light microscopy. the renal pathology society/ international society of nephrology (ISN/RPS) 2003 revised criteria were used to classify the kidney biopsy especially histopathology according to Pathological types like as chronic indices (CI) and active indices (AI) were recorded by using the semi-quantitative method of especial biopsy features. The deposition of $\mathrm{IgG}$ in renal biopsy was detected by direct immunohistochemistry stain. Kidney biopsies were stained with a 3, 30-Diaminobenzidine (DAB). positive cells were estimated by numbered images using pro plus software images.

\section{Statistical Analysis:}

The data was statistically analyzed by using a statistical package for social scie- nces (IBM-SPSS), version 24 (May 2016); IBM- Chicago, USA. Data were expressed as a descriptive value for quantitative data as (mean, standard deviation (SD), number, and percentage). Student t-test was used to compare the means between the two groups. When the data are non-parametric was used Mann Whitney test instead of the Student t-test. Percentages of qualitative variables were compared by Pearson Chi-square test, and Fisher exact test was used instead of ordinary chi-square test in cases of non-parametric data.

The level of significance (P-value) of these test can be explained as:

- No significance $\mathrm{P}>0.05$

- Significance $\mathrm{P}<0.05$

- High significance $P<0.001$

\section{Results:}

This study was conducted from October 2018 to July 2019 in the Rheumatology Department, Sohag University Hospital. 70 SLE patients with lupus nephritis were included in this study with 64 females $(91.4 \%)$ and 6 males $(8.6 \%)$ with the age of our patients ranged from 18 to 66 years, the mean was $30.71 \pm 11.520$, the duration of the disease ranged from 5 to 156 months with a mean of 39 months table 1.

In our study, the clinical relationships of positivity of the three antibodies were determined together (3-pos) as an indicator of the severe activity of the kidney affection, the three pos group $(n=16)$ and non three pos $(n=54)$ in a group of 70 $\mathrm{LN}$ were matched according to serological parameters and clinical data. Firstly, age was a significant difference between two groups ( 3-positive and non-positive of $\mathrm{LN}$ patients) with $\left(\mathrm{P}=0.015^{*}\right)$, table 1. According to the prevalence of autoantibodies, in our study, we found that AntiDs DNA was the most frequent antibody 
SOHAG MEDICAL JOURNAL

Vol. 25 No. 1 Jan 2021 that appeared in LN patients then followed by Anti-Nucleosome, Anti-Ro60KD, Anti-Ro52KD, and Anti-Histones by percentage $(62.9 \%, 44.2 \%, 34.3 \%, 31.4 \%$, and $30 \%$ respectively) but the least frequent antibody was Anti-Mi-2 by percentage $(0 \%)$ table 2.

So in class, I + II and class V the 3 pos antibodies prevalence versus Non-3pos was $(0 / 0 \%, 18.8 / 50 \%, 6.3 / 16.6 \%$ respectively) but in class III + IV was $(25 / 24 \%$, $38.5 / 9.2 \%$ respectively) which act as strong indicator. correlation between the 3pos and the activity of the kidney affection, especially $4^{\text {th }}$ degree of nephritis (proliferative glomerulonephritis), and the capability of three positive to portend progression of kidney affection may lead to big added advantages in the follow-up of LN patients figure1.

We estimate the titers of three auto-antibodies ( anti-nucleosome, -histone and anti-dsDNA) in three pos and non-pos SLE patients especially in LN patients, we considered the non-3pos patient whose serum level of three antibodies( negative titer or single, double antibodies positive titer associated with each other . in our study, we found the three antibodies level in a different class of $\mathrm{LN}$ were highly significant in three pos group than in the non three pos with ( $\mathrm{p}$-value $=$ 0.002 ) table $3,4,5$.

We found the highest frequent histological type of LN was class IV(diffuse proliferative glomerulonephritis) which common to occur in three pos than in non three pos groups (38.5\%vs. 9.2\%), Furthermore, the prevalence of (nuclsome ,DSDNA ,Histone) autoantibodies in (class
$\mathrm{III}+\mathrm{IV})(17 / 28,60.8 \% \mathrm{P}$ nuc $=$ $\left.0.041^{*}\right)$ table $3,(20 / 28,71.4 \% \mathrm{P}$ ds$\mathrm{DNA}=0.140) \quad, \quad(10 / 28,35.7 \%, \quad \mathrm{P}$ his $\left.=0.05^{*}\right)$ respectively was highly significant than in (class I + II) $(8 / 30,26.7 \%$, $\mathrm{P}$ nuc $\left.=0.010^{*}\right)$ table 3, $(15 / 30,50 \%, \mathrm{P}$ ds-DNA = 0.054)table 4, $(8 / 30,26.7 \% \mathrm{P}$ his $=0.598)$ table5 respectively and those with membranous lesions (class V) $(3 / 10,30 \%, \mathrm{P}$ nuc $=0.523),(6 / 10,60 \%$, $\mathrm{P}$ ds-DNA $=0.449)$ table $4(1 / 10,10 \% \mathrm{P}$ his $=0.087$ ) table $\mathbf{5}$.

In our study, The medians of $24 \mathrm{hr}$ of protein in the urine, s.creatinine, and pus cells in urine analysis were all highly significant in three pos antibodies group than non three pos antibodies group (pvalue $=0.001 *, 0.31$ and 0.009 respectively) high level of albumin (Albumin+++) in urine was found in 3 pos more than non three pos $(56.25 \%, 20.3 \%$ respectively) with p-value approached significant $(\mathrm{p}=0.06)$, Additionally, we found that There was a non-significant difference between both groups regarding urinary RBCS and cast, although hemoglobin HB level $(\mathrm{g} / \mathrm{L})$, in three pos patients, were low significant than in non three pos patients with $\left(\mathrm{p}\right.$-value $\left.=0.043^{*}\right)$, But We detected that the count of white blood cell (WBC) and platelets (PLT)levels were no significant difference between three pos patients and non three pos patients table 1 .

In our study, the frequency of 3POS and SELDAI score was anti-ds DNA being more frequent in moderate disease activity followed by nucleosome than histone antibody, the same frequency was found in severe disease activity, figure 2 
SOHAG MEDICAL JOURNAL

Vol. 25 No. 1 Jan 2021
Correlation between the activity of lupus nephritis Alaa Mohamed Hemdan

\begin{tabular}{|c|c|c|c|c|}
\hline Index & & 3 pos (16) & 3Non pos (54) & $\mathrm{P}$ value \\
\hline \multirow{2}{*}{ Age (years) } & Mean \pm SD & $25.00 \pm 9.473$ & $32.26 \pm 11.821$ & \multirow[t]{2}{*}{$0.015^{*}$} \\
\hline & Median (range) & $22.50(16-31)$ & $30.00(12-66)$ & \\
\hline \multirow[t]{2}{*}{ Duration(months) } & Mean \pm SD & $27.94 \pm 11.210$ & $42.54 \pm 35.378$ & \multirow[t]{2}{*}{0.352} \\
\hline & Median (range) & $24.00(9-48)$ & $36.00(5-156)$ & \\
\hline \multirow[t]{2}{*}{ Urinary protein $(\mathrm{g} / 24 \mathrm{~h})$} & Mean \pm SD & $3.052 \pm 3.1273$ & $1.521 \pm 2.0904$ & \multirow[t]{2}{*}{$0.001 *$} \\
\hline & Median (range) & $2.280(.7-13.5)$ & $0.800(0-9.9)$ & \\
\hline \multirow[t]{2}{*}{ Urinary RBC (n/HP) } & Mean \pm SD & $3.44 \pm 6.511$ & $5.22 \pm 16.768$ & \multirow[t]{2}{*}{0.354} \\
\hline & Median (range) & $.00(0-20)$ & $0.00(0-90)$ & \\
\hline \multirow[t]{2}{*}{ Urinary pus cell $(\mathrm{n} / \mathrm{HP})$} & Mean \pm SD & $31.25 \pm 31.064$ & $13.63 \pm 26.601$ & \multirow[t]{2}{*}{$0.009 *$} \\
\hline & Median (range) & $25.00(0-90)$ & $0.00(0-100)$ & \\
\hline \multirow[t]{2}{*}{$\mathrm{SCr}(\mu \mathrm{mol} / \mathrm{L})$} & Mean \pm SD & $1.504 \pm 1.1670$ & $0.836 \pm .3945$ & \multirow[t]{2}{*}{$0.031 *$} \\
\hline & Median (range) & $1.035(.5-4.2)$ & $0.700(.4-2.3)$ & \\
\hline \multirow[t]{2}{*}{ WBC } & Mean \pm SD & $6.219 \pm 3.4772$ & $6.287 \pm 3.3415$ & \multirow[t]{2}{*}{0.850} \\
\hline & Median (range) & $4.700(2.3-13.8)$ & $5.900(1.4-17)$ & \\
\hline \multirow[t]{2}{*}{ PLT } & Mean \pm SD & $204.97 \pm 86.918$ & $246.55 \pm 114.597$ & \multirow[t]{2}{*}{0.334} \\
\hline & Median (range) & $213.50(40-367)$ & $219.50(31-711)$ & \\
\hline \multirow[t]{2}{*}{$\mathrm{HB}(\mathrm{g} / \mathrm{L})$} & Mean \pm SD & $9.312 \pm 2.5351$ & $10.570 \pm 2.0132$ & \multirow[t]{2}{*}{$0.043 *$} \\
\hline & Median (range) & $9.600(5.5-13)$ & $10.500(4.0-14.5)$ & \\
\hline \multirow[t]{2}{*}{ ANA } & Negative & $0(0 \%)$ & $0(0 \%)$ & \multirow[t]{2}{*}{----} \\
\hline & Positive & $16(100 \%)$ & $54(100 \%)$ & \\
\hline \multirow[t]{2}{*}{ Anti Sm/RNP } & Negative & $7(43.7 \%)$ & $46(85.1 \%)$ & \multirow[t]{2}{*}{$0.001 *$} \\
\hline & Positive & $9(56.2 \%)$ & $8(14.8 \%)$ & \\
\hline \multirow[t]{2}{*}{ Anti-Sm } & Negative & $9(56.2 \%)$ & $46(85.1 \%)$ & \multirow[t]{2}{*}{$0.013^{*}$} \\
\hline & Positive & $7(43.7 \%)$ & $8(14.8 \%)$ & \\
\hline \multirow[t]{2}{*}{ Anti-RNP } & Negative & $8(50 \%)$ & $44(81.5 \%)$ & \multirow[t]{2}{*}{$0.011 *$} \\
\hline & Positive & $8(50 \%)$ & $10(18.5 \%)$ & \\
\hline \multirow[t]{2}{*}{ Anti-ribosomal-P } & Negative & $8(50 \%)$ & $51(94.4 \%)$ & \multirow[t]{2}{*}{$<0.0001 *$} \\
\hline & Positive & $8(50 \%)$ & $3(5.5 \%)$ & \\
\hline
\end{tabular}

Table 1. Baseline laboratory characteristics between 3-pos and non-3-pos patients with LN.

\begin{tabular}{|c|c|c|}
\hline ANA profile & Frequencies & Percent \\
\hline Anti-Sm & 15 & $(21.4 \%)$ \\
\hline Anti-RNP & 18 & $(25.7 \%)$ \\
\hline Anti-Sm/ RNP & 17 & $(24.3 \%)$ \\
\hline Anti-Ro60KD & 24 & $(34.3 \%)$ \\
\hline Anti-Ro52KD & 22 & $(31.4 \%)$ \\
\hline Anti-SS-B/La & 9 & $(12.9 \%)$ \\
\hline Anti-SCL70 & 2 & $(2.9 \%)$ \\
\hline Anti-Ku & 2 & $(2.9 \%)$ \\
\hline Anti-PM-scl100 & $6 x$ & $(8.6 \%)$ \\
\hline Anti-Mi-2 & 0 & $(0 \%)$ \\
\hline Anti-Jo-1 & 2 & $(2.9 \%)$ \\
\hline Anti-CENP-A/B & 4 & $(5.7 \%)$ \\
\hline Anti-PCNA & 6 & $(8.6 \%)$ \\
\hline Anti-Ribosomes Po & 11 & $(15.7 \%)$ \\
\hline antiphospholipid & 1 & $(1.4 \%)$ \\
\hline Anti-DFS-70 & 7 & $(10 \%)$ \\
\hline Anti-Ds DNA & 44 & $(62.9 \%)$ \\
\hline Anti-Nucleosome & 31 & $(44.2 \%)$ \\
\hline Anti-Histones & 21 & $(30 \%)$ \\
\hline
\end{tabular}

\begin{tabular}{|l|c|c|c|}
\hline $\begin{array}{l}\text { Renal } \\
\text { class }\end{array}$ & \multicolumn{2}{|c|}{ Anti-Nuclsome } & $\begin{array}{c}\text { P } \\
\text { value }\end{array}$ \\
\hline & Positive & Negative & \\
\hline I $(\mathrm{n}=0)$ & 0 & 0 & - \\
\hline II $(\mathrm{n}=30)$ & $8(26.7 \%)$ & $22(73.4 \%)$ & $0.010^{*}$ \\
\hline III $(\mathrm{n}=17)$ & $9(52.9 \%)$ & $8(47.0 \%)$ & 0.409 \\
\hline IV $(\mathrm{n}=11)$ & $8(72.7 \%)$ & $3(27.7 \%)$ & $0.041 *$ \\
\hline V $(\mathrm{n}=10)$ & $3(30 \%)$ & $7(70 \%)$ & 0.523 \\
\hline VI $(\mathrm{n}=2)$ & $2(100 \%)$ & $0(0 \%)$ & 0.193 \\
\hline
\end{tabular}

Table 3.Comparison between lupus nephritis class and anti-Nuclsome antibody

Table 2. the prevalence of autoantibodies in lupus nephritis patients 
SOHAG MEDICAL JOURNAL

Vol. 25 No. 1 Jan 2021

\begin{tabular}{|l|c|c|c|}
\hline $\begin{array}{l}\text { Renal } \\
\text { class }\end{array}$ & \multicolumn{2}{|c|}{ Anti-ds DNA } & $\begin{array}{c}\text { P- } \\
\text { value }\end{array}$ \\
\hline & Positive & Negative & \\
\hline I (n=0) & 0 & 0 & - \\
\hline II (n=30) & $15(50 \%)$ & $15(50 \%)$ & $0.054 *$ \\
\hline III (n=17) & $11(64.7 \%)$ & $6(35.3 \%)$ & 0.856 \\
\hline IV (n=11) & $9(81.8 \%)$ & $2(18.8 \%)$ & 0.140 \\
\hline V (n=10) & $6(60 \%)$ & $4(40 \%)$ & 0.449 \\
\hline VI (n=2) & $2(100 \%)$ & $0(0 \%)$ & 0.392 \\
\hline
\end{tabular}

Table 4. Comparison between lupus nephritis class and anti-ds-DNA antibody

\begin{tabular}{|l|c|c|c|}
\hline $\begin{array}{l}\text { Renal } \\
\text { class }\end{array}$ & \multicolumn{2}{|c|}{ Anti-Histone } & $\begin{array}{c}\text { P- } \\
\text { value }\end{array}$ \\
\hline & Positive & Negative & \\
\hline I (n=0) & 0 & 0 & - \\
\hline II (n=30) & $8(26.7 \%)$ & $22(73.4 \%)$ & 0.598 \\
\hline III (n=17) & $4(23.5 \%)$ & $13(76,6 \%)$ & 0.365 \\
\hline IV (n=11) & $6(54.5 \%)$ & $5(45.5 \%)$ & 0.053 \\
\hline V (n=10) & $1(10 \%)$ & $9(90 \%)$ & 0.129 \\
\hline VI (n=2) & $2(100 \%)$ & $0(0 \%)$ & 0.087 \\
\hline
\end{tabular}

Table 5. Comparison between lupus nephritis class and anti Histone antibody
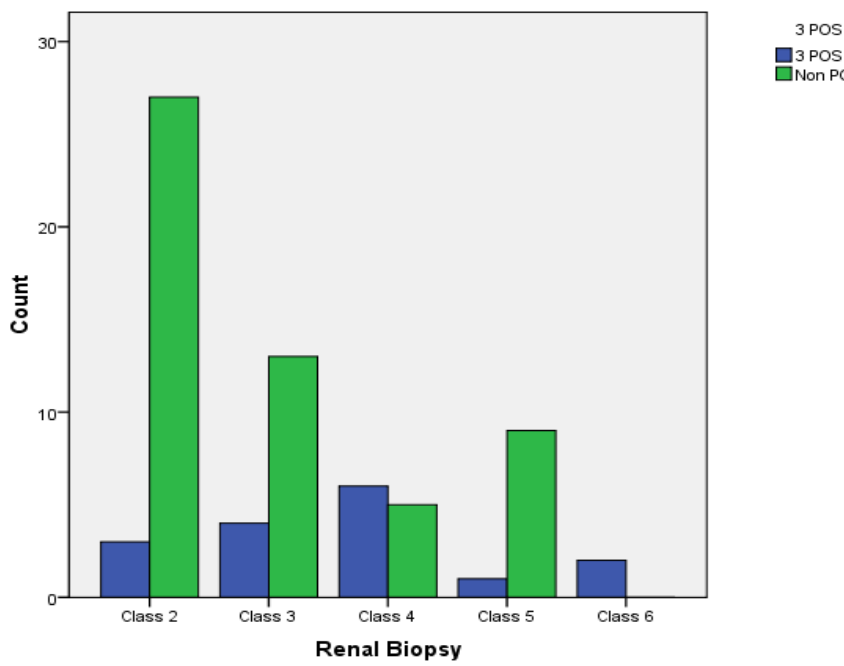

$\square_{\text {Non POS }}$
Pon

Figure 1. Comparison between lupus nephritis class and 3 positive antibodies.

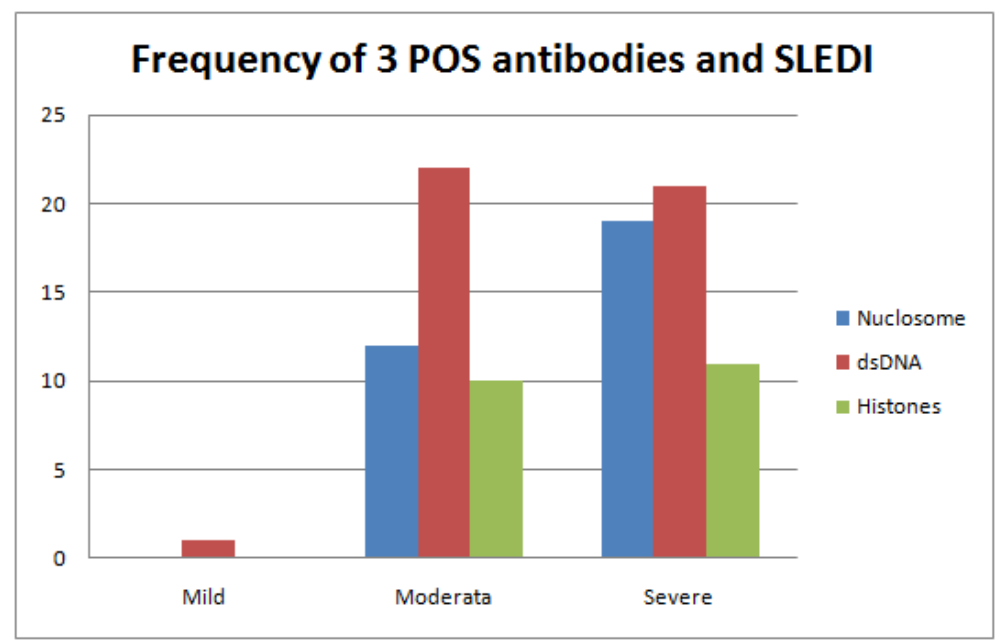

Figure 2. Frequency of 3POS antibodies and SLEDAI 


\section{Discussion}

In this study, we retrospectively analyzed a group of clinical data of 70 patients of SLE with a cohort study from October 2018 to July 2019 in the Rheumatology Department, Sohag University Hospital, we detected that simultaneous correlation of anti-histone,-nucleosome, and dsDNA antibodies (three pos) in patients of SLE with the disease activity.

In our study, the clinical relationships of positivity of the three antibodies were determined together (three pos) as an indicator of the severe activity of the kidney affection, the three pos group ( $\mathrm{n}=$ 16) and non three pos $(n=54)$ in a group of $70 \mathrm{LN}$ were matched according to serological parameters and clinical data. Firstly, the age was a significant difference between two groups ( 3positive and non-positive of $\mathrm{LN}$ patients) with $\left(\mathrm{P}=0.015^{*}\right),[8]$ showed different results they reported that the age was balanced between both groups.

Regarding the prevalence of autoantibodies, in our study we found that AntiDs DNA was the most frequent antibody that appeared in LN patients by percentage $(62.9 \%)$ then followed by AntiNucleosome (44.2\%) then Anti-Ro60KD, Anti-Ro52KD, and Anti-Histones by percentage $(34.3 \%, 31.4 \%$, and $30 \%$ respectively but the least frequent antibody was Anti-Mi-2 by percentage $(0 \%)$ this was near to the results of Kamen et al. and Yang et al., who found 921 patients of SLE with lupus nephritis, the autoantibodies (anti -nucleosome, -histone,-dsDNA, and anti-mitochondrial-2 antibodies) were (63.3\%), (59.8\%),(49.3\%) and (8.3\%) patients respectively, which Highly significant than those in 778 patients without nephritis $(9,10)$.

So in class, I + II and class V the 3 pos antibodies prevalence versus Non-3pos was $(0 / 0 \%, 18.8 / 50 \%, 6.3 / 16.6 \%$; respectively) but in class III + IV was (25/24\%,38.5/9.2\% respectively) which act as strong indicator. correlation between the 3-pos and the activity of the kidney affection, especially $4^{\text {th }}$ degree of nephritis (proliferative glomerulonephritis), and The capability of three positive to portend progression of kidney affection may lead to big added advantages in the follow-up of $\mathrm{LN}$ patients this was near to the result of van Bavel et al. and Ng et al., who found Patients with antiNCS antibody high level during the Serologically active clinically quiescent period of SLE (SACQ) had a significant correlation with disease flare spotted $(\mathrm{r}=$ $0.57, \mathrm{P}=0.007$ ), Although This correlation was not detected with anti- dsDNA level $(r=0.13, \mathrm{P}=0.58)(\mathbf{1 1}, \mathbf{1 2})$.

Our results were in line with the results of Sui et al., who observed that antihistone, anti- nucleosome, and -dsDNA antibodies were auto-antibodies with a nephritogenic effect which highly associated with the occurrence of lupus nephritis in a large number of SLE patients; the close relation of the three antibodies may indicate severe activity of kidney disease and management in LN patients (8).

We estimate the titers of three autoantibodies ( anti-nucleosome, -histone, and anti-dsDNA) in three pos and nonpos SLE patients especially LN, we considered the non-3pos patient whose serum level of three antibodies( negative or single, double association with them. in our study, we found the three antibodies level were highly significant in three pos. group than in the non three pos with (pvalue $=0.002$ ) which was in agreement with Yang et al., Mjelle et al. and O'Flynn et al $(10,13,14)$. 
SOHAG MEDICAL JOURNAL

Vol. 25 No. 1 Jan 2021
We found the highest frequent histologyical type of LN was class IV(d-iffuse proliferative glomerulonephritis) which common to occur in three pos than in non three pos groups (38.5\% vs. $9.2 \%)$, Furthermore, the prevalence of (nuclso-me ,DS-DNA ,Histone) autoantibodies in (class III + IV) $(17 / 28,60.8 \% \mathrm{P}=$ $0.041),(20 / 28,71.4 \% \mathrm{P}$ ds-DNA $=0.1-$ $40),(10 / 28,35.7 \%, \mathrm{P}=0.05)$ respectively was highly significant than in (class $\mathrm{I}+$ II) $\left(8 / 30,26.7 \%, \mathrm{P}\right.$ nuc $\left.=0.010^{*}\right)$, $(15 / 30,50 \%, \mathrm{P}$ ds-DNA $=0.054),(8 / 30$, $26.7 \% \mathrm{P}$ his $=0.598$ )respectively and those with (class V) $(3 / 10,30 \%, \mathrm{P}$ nuc $=$ $0.523),(6 / 10,60 \%, \mathrm{P}$ ds-DNA $=0.449)$, $(1 / 10,10 \% \mathrm{P}$ his $=0.087)$, this was near to the results of Mjelle et al., who found that the prevalence of the three outaantibodies were $(61.52 \%$ vs. $34.11 \%$, $\mathrm{P}<0.0001), \quad(49.35 \%$ vs. $33.33 \%$, P00.0013) and ( $56.09 \%$ vs. $37.21 \%$, P00.0002) of anti-dsDNA, anti-histone and anti-nucleoso-me antibodies respectively in lupus neph-ritis patients with were highly significant than that in SLE patients without lupus nephritis, that mean the 3-pos Patients were high risky of proliferative kidney disease (13).

In our study, The medians of $24 \mathrm{hr}$ of protein in the urine, s.creatinine, and pus cells in urine analysis were all highly significant in three pos antibodies group than non three pos antibodies group (pvalue $=0.001 *, 0.31$ and 0.009 respectively) high level of albumin (Albumin+++) in urine was found in 3 pos more than non three pos $(56.25 \%, 20.3 \%$ respectively) with $\mathrm{p}$-value approached significant $(p=0.06)$, These findings are in agreement with Yang et al., who found that The medians of $24 \mathrm{hr}$ excretion of protein in the urine,s. creatinine and( pus cells, RBCs, WBCs) in urine analysis were all highly significant in the three pos group than non three pos antibodies group $(p<0.0001)$ for all comparisons (10).

Additionally, we found that There was a non-significant difference between both groups regarding urinary RBCS and cast, although hemoglobin $\mathrm{HB}$ level $(\mathrm{g} / \mathrm{L})$, in three pos patients were low significant than in non three pos patients with (pvalue $\left.=0.043^{*}\right)$, But We detected that the count of white blood cell (WBC) and platelets (PLT)levels were no significant difference between three pos patients and non three pos patients, but Mahmoud et al., found that urinary cast and RBCs were highly significant in lupus nephritis patients (15).

Our study suggests that close reactivity to three outa-antibodies( anti- nucleosome, histone, and dsDNA) antibodies (3-pos) in SLE patients was highly relevant to the pathology of lupus nephritis. LN patients with 3-pos showed highly significant serum levels of three antibodies, suffered from more highly kidney damage, and needed more aggressive treatment than non-3-pos groups, indicating 3-pos antibodies act as a biomarker for severe renal affection in lupus patients, These findings are in agreement with Sui et al., Yang et $a l$. and Shabana et al $(5,8,10)$.

In our study, The three autoantibodies were more frequent in mild, moderate, and severe disease activity score with anti-dsDNA being more frequent in moderate disease activity followed by nucleosome than histone antibody, the same frequency was found in severe disease activity, These findings are in agreement with Narayanan et al., who found that The anti-dsDNA levels were elevated in all cases with major kidney flare but only elevated in 35\% cases of nonkidney flare. Positivity correlation was detected between anti-dsDNA level and SLEDAI score (0.01 level two-tailed prediction). Estimation of SLEDAI is an 
important clinical tool for the evaluation of SLE patients. Serial detection of antidsDNA level informed us about lupus acactivity and the appropriate therapy for lupus patients with a high score of SLEDI (16).

\section{Conclusion:}

ANA profile (IgG) especially the 3 autoantibodies (anti-dsDNA, - histone, and nucleosome antibodies) may be used as indicators for severe renal affection in SLE patients.

\section{References:}

1. Rahman A, Isenberg DA. Systemic lupus erythematosus. $\mathrm{N}$ Engl J Med. 2008;358(9):929-39.

2. Riemekasten G, Hahn BH. Key autoantigens in SLE. Rheumatology (Oxford). 2005;44(8):975-82.

3. Fanouriakis A, Krasoudaki E, Tzanakakis M, Boumpas DT. Recent progress in the treatment of lupus nephritis. Mod Rheumatol. 2012;22(6):803-13.

4. Nowling TK, Gilkeson GS. Mechanisms of tissue injury in lupus nephritis. Arthritis Res Ther. 2011;13(6):250.

5. Shabana AA, El-Ghawet AE, Machaly SA, Abu Hashim EM, El-Kady BA, Shaat R. Anti-chromatin and anti-histone antibodies in Egyptian patients with systemic lupus erythematosus. Clin Rheumatol. 2009;28(6):673-8.

6. Isenberg DA, Ravirajan CT, Rahman A, Kalsi J. The role of antibodies to DNA in systemic lupus erythematosus--a review and introduction to an international workshop on DNA antibodies held in London, May 1996. Lupus. 1997;6(3):290-304.

7. Sherer Y, Gorstein A, Fritzler MJ, Shoenfeld Y. Autoantibody explosion in systemic lupus erythematosus: more than 100 different antibodies found in SLE patients. Semin Arthritis Rheum. 2004;34(2):501-37.

8. Sui M, Lin Q, Xu Z, Han X, Xie R, Jia X, et al. Simultaneous positivity for antiDNA, anti-nucleosome, and anti-histone antibodies are a marker for more severe lupus nephritis. J Clin Immunol. 2013;33(2):378-87.

9. Kamen DL, Barron M, Parker TM, Shaftman SR, Bruner GR, Aberle T, et al. Autoantibody prevalence and lupus characteristics in a uniquely African American population. Arthritis Rheum. 2008;58(5):1237-47.

10. Yang J, Xu Z, Sui M, Han J, Sun L, Jia X, et al. Co-Positivity for Anti-dsDNA, Nucleosome and -Histone Antibodies in Lupus Nephritis Is Indicative of High Serum Levels and Severe Nephropathy. PLoS One. 2015;10(10):e0140441.

11.van Bavel CC, Fenton KA, Rekvig OP, van der Vlag J, Berden JH. Glomerular targets of nephritogenic autoantibodies in systemic lupus erythematosus. Arthritis Rheum. 2008;58(7):1892-9.

12.Ng KP, Manson JJ, Rahman A, Isenberg DA. Association of antinucleosome antibodies with disease flare in serologically active clinically quiescent patients with systemic lupus erythematosus. Arthritis Rheum. 2006;55(6):900-4.

13.Mjelle JE, Rekvig OP, Van Der Vlag J, Fenton KA. Nephritogenic antibodies bind in glomeruli through interaction with exposed chromatin fragments and not with renal cross-reactive antigens. Autoimmunity. 2011;44(5):373-83.

14. O'Flynn J, Flierman R, van der Pol P, Rops A, Satchell SC, Mathieson PW, et al. Nucleosomes and $\mathrm{Clq}$ bound to glomerular endothelial cells serve as targets for autoantibodies and determine complement activation. Mol Immunol. 2011;49(1-2):75-83.

15. Mahmoud GA, Zayed HS, Ghoniem SA. Renal outcomes among Egyptian lupus nephritis patients: a retrospective analysis of 135 cases from a single center. Lupus. 2015;24(3):331-8.

16. Narayanan K, Marwaha V, Shanmuganandan K, Shankar S. Correlation between systemic lupus erythematosus disease activity index, C3, C4, and anti-dsDNA antibodies. Medical 
SOHAG MEDICAL JOURNAL Correlation between the activity of lupus nephritis

Vol. 25 No. 1 Jan 2021

Journal Armed Forces India.

2010;66(2):102-7. 